\title{
Observed Total Body Clearance by Fraction of Dose Absorbed
}

National Cancer Institute

\section{Source}

National Cancer Institute. Observed Total Body Clearance by Fraction of Dose Absorbed. NCI Thesaurus. Code C85772.

The observed total body clearance for extravascular administration, where $\mathrm{F}$ is the fraction of dose absorbed. 